\title{
The Effect of Zeolite Features on Catalytic Performances of Cuznzr/Zeolite Hybrid Catalysts in One-pot CO2-to-DME Hydrogenation
}

\author{
Enrico Catizzone $^{1 *}$, Giuseppe Bonura ${ }^{2}$, Massimo Migliori ${ }^{3}$, Giacobbe Braccio ${ }^{1}$, Francesco Frusteri ${ }^{2}$, Girolamo Giordano ${ }^{3}$ \\ ${ }^{1}$ ENEA-Italian National Agency for New Technologies, Energy and Sustainable Economic Development, Trisaia Research \\ Centre, I-75026, Rotondella, Italy \\ ${ }^{2}$ CNR-ITAE, Istituto di Tecnologie Avanzate per l'Energia “Nicola Giordano”, via S. Lucia Sopra Contesse, 5, I-98126, \\ Messina, Italy \\ ${ }^{3}$ University of Calabria, Dept. of Environmental and Chemical Engineering, via P. Bucci, 44a, I-87036, Rende, Italy
}

Corresponding Author Email: enrico.catizzone@enea.it

https://doi.org/10.18280/ti-ijes.632-420

Received: 28 January 2019

Accepted: 24 April 2019

Keywords:

$\mathrm{CO}_{2}$ recycling, dimethyl ether,

heterogeneous catalysis, zeolites

\begin{abstract}
The production of DME from $\mathrm{CO}_{2}$ hydrogenation is a way of recycling $\mathrm{CO}_{2}$ and it requires the use of a hybrid multifunctional catalyst to efficiently catalyze the two consecutive reaction paths of methanol synthesis and methanol dehydration directly in one single step. The aim of this work is to investigate the utilization of zeolite-based catalysts for dimethyl ether synthesis by assessing the role of catalyst features in both methanol dehydration and one-pot $\mathrm{CO}_{2}$ hydrogenation.

Obtained results, discussed in terms of turnover frequency reveal that FER-type zeolite prepared with $\mathrm{Si} / \mathrm{Al}=10$ exhibits the best performances during vapor-phase methanol dehydration whilst the efficiency of $\mathrm{CO}_{2}$-to-DME process strongly depends on the way in which metallic and acidic materials are coupled. Single grain prepared via gel-oxalate precipitation of $\mathrm{CuZnZr}$ over zeolite crystals exhibit the best performances in terms of $\mathrm{CO}_{2}$ conversion and DME productivity.
\end{abstract}

\section{INTRODUCTION}

The utilization of $\mathrm{CO}_{2}$ as carbon source represents a reliable strategy to recycle "environmentally unfriendly" compounds in the production chain of chemicals currently produced from fossil carbon source [1-2].

In this concern, the production of dimethyl ether (DME) via $\mathrm{CO}_{2}$ hydrogenation permits to obtain an alternative and sustainable Diesel fuel [3-5].

Actually DME is produced from fossil-derived syngas, through two gas-phase routes according to the indirect or direct synthesis path. In the indirect route, methanol $(\mathrm{MeOH})$ is synthesized by $\mathrm{CO}$ hydrogenation over conventional $\mathrm{Cu} / \mathrm{ZnO} / \mathrm{Al}_{2} \mathrm{O}_{3}$ catalysts and then dehydrated to DME over an acid catalyst in a separate reactor. In the direct route, DME is synthesized from syngas in "one pot" over a bi-functional catalyst under process conditions close to those of methanol synthesis (240-280 $\left.{ }^{\circ} \mathrm{C}, 3-7 \mathrm{MPa}\right)$ [6-8].

The "one-step" route is more efficient than the "double-step" route, mainly because of thermodynamic advantages related to the equilibrium shift of simultaneous reactions (methanol dehydration to DME promotes the syngas conversion) and for a lower overall process cost. In addition, valorization and reusing of carbon dioxide is an important challenge in order to mitigate the growing global warming due to greenhouse gas emission [9-10]. On this account, more and more attention is receiving the synthesis of DME by total or partial replacement of $\mathrm{CO}$ with $\mathrm{CO}_{2}$ [11-16].

In the one-pot $\mathrm{CO}_{2}$ hydrogenation process, the DME synthesis net reaction is given by the following reaction:
$2 \mathrm{CO}_{2}+6 \mathrm{H}_{2}=\mathrm{CH}_{3} \mathrm{OCH}_{3}+3 \mathrm{H}_{2} \mathrm{O}$

involving the following consecutive steps:

$\mathrm{CO}_{2}+3 \mathrm{H}_{2}=\mathrm{CH}_{3} \mathrm{OH}+\mathrm{H}_{2} \mathrm{O}$

$2 \mathrm{CH}_{3} \mathrm{OH}=\mathrm{CH}_{3} \mathrm{OCH}_{3}+\mathrm{H}_{2} \mathrm{O}$

DME synthesis reaction is an exothermic reaction that releases about $122 \mathrm{~kJ}$ of heat for each DME mol produced. For this reason, from a thermodynamic point of view, a decrease in reaction temperature should favor the synthesis of DME.

Furthermore, high pressure also should favor DME production since the reaction occurs with a reduction of total moles. Nevertheless, $\mathrm{CO}_{2}$ is not a highly reactive molecule and temperatures above $240{ }^{\circ} \mathrm{C}$ are usually requested for facilitating $\mathrm{CO}_{2}$ activation rate. High reaction temperature favors endothermic side reactions such as reverse water gas shift:

$\mathrm{CO}_{2}+\mathrm{H}_{2}=\mathrm{CO}+\mathrm{H}_{2} \mathrm{O}$

Furthermore, hydrocarbons and coke may be formed during such process. Therefore, highly active and selective catalyst is required to avoid the formation of undesired by-product. Anyhow, irrespective of the process applied for the DME synthesis, it has been demonstrated that the properties of the acid matrix significantly affect selectivity and durability of bifunctional catalyst as well as the overall process efficiency, being controlled by the dehydration step [17-18]. 
Several studies have been carried out using $\gamma-\mathrm{Al}_{2} \mathrm{O}_{3}$ as acid catalyst reporting high selectivity towards DME formation in the temperature range $200-300{ }^{\circ} \mathrm{C}$, but also rapid deactivation by water adsorption on Lewis acid sites, especially during the direct synthesis via $\mathrm{CO}_{2}$ hydrogenation where a lot amount of water is formed from both methanol dehydration and reversewater-gas-shift reaction [19]. So, a more hydrophobic acid catalyst is suggested to be used in this gas-to-liquid reaction. As alternative to $\gamma-\mathrm{Al}_{2} \mathrm{O}_{3}$, zeolites have been also investigated revealing a better stability to water and higher methanol conversion [20-24].

Activity, selectivity and stability of zeolites applied in acidcatalyzed reactions are recognized to depend upon several factors as zeolite structure, acidity and crystal size. Zeolite channel system (channel orientation and opening size) is a well-known factor affecting strongly products distribution and catalyst deactivation [25-27].

Acid sites concentration and density, typology (Brønsted and Lewis), strength and location are also important parameters to tune carefully when zeolites are applied in catalysis [28-29].

Furthermore, catalyst resistance to deactivation as well as catalyst effectiveness can be improved by changing size and morphology of zeolite crystals. In particular, application of nano-sized or hierarchical zeolite crystals permits to reduce coke formation and enhance diffusion of reactant species improving catalyst performances [30-31].

Therefore, the ability of a zeolite to offer chemical-physical properties control in both in situ and post-synthesis treatments is of considerable importance for industrial applications.

FER-type and MFI-type structure disclosed reliable shapeselectivity towards DME synthesis although more details about the role of acid sites should be better elucidate [32-33].

In this paper, a step by step optimization of the catalyst for DME synthesis is reported. The effect of zeolite structure and acidity on methanol dehydration reaction step is assessed by comparing catalytic performances of FER- and MFI-type zeolites with different acidity. Once the best catalyst for methanol dehydration has been identified, the metal/acidic multifunctional catalytic bed configuration was optimized aiming to obtain high DME productivity during one-pot $\mathrm{CO}_{2-}$ to-DME process.

\section{MATERIALS AND METHODS}

In order to investigate the effect of zeolite features on the DME synthesis, FER-type and MFI-type zeolites with different acidity were synthesized by varying the $\mathrm{Si} / \mathrm{Al}$ ratio, from 10 to 60 . In particular MFI-type zeolites with different acidity level were prepared using tetrapropyl ammonium bromide (TPABr) as structure directing agent (SDA) by starting from a gel with the following molar composition:

$$
10 \mathrm{Na}_{2} \mathrm{O}-8 \mathrm{TPABr}-100 \mathrm{SiO}_{2}-\mathrm{x} \mathrm{Al}_{2} \mathrm{O}_{3}-2000 \mathrm{H}_{2} \mathrm{O}
$$

where $\mathrm{x}=1,2$ and 3.3 according to the expected $\mathrm{Si} / \mathrm{Al}$ molar ratio of 15,25 and 50 , respectively.

The crystallization was carried out in a Teflon-lined stainless steel autoclave kept at $175^{\circ} \mathrm{C}$ for 5,4 and 2 days for sample prepared with $\mathrm{Si} / \mathrm{Al}$ equals to 15,25 and 50 , respectively. Details on the reactants and procedure are reported elsewhere [34].
Pyrrolidine was used as SDA for synthesizing FER-type zeolite with $\mathrm{Si} / \mathrm{Al}=10$, whilst pyridine was used for FER30 and FER 60 by adopting the following synthesis molar gel composition, respectively:

$8 \mathrm{Na}_{2} \mathrm{O}-60$ Pyridine $-100 \mathrm{SiO}_{2}-5 \mathrm{Al}_{2} \mathrm{O}_{3}-2000 \mathrm{H}_{2} \mathrm{O}$

$9 \mathrm{Na}_{2} \mathrm{O}-60$ Pyrrolidine $-100 \mathrm{SiO}_{2}-1.7 \mathrm{Al}_{2} \mathrm{O}_{3}-2500 \mathrm{H}_{2} \mathrm{O}$

$9 \mathrm{Na}_{2} \mathrm{O}-60$ Pyrrolidine $-100 \mathrm{SiO}_{2}-0.8 \mathrm{Al}_{2} \mathrm{O}_{3}-2500 \mathrm{H}_{2} \mathrm{O}$

Crystallization was carried in a Teflon-lined stainless steel autoclave rotated with a speed of $20 \mathrm{rpm}$ and kept at $175^{\circ} \mathrm{C}$ for 3 days for FER (10) and at $165^{\circ} \mathrm{C}$ for 5 days for FER (30) and FER (60).

All the crystallized samples were separated from mother liquor by vacuum filtration and washed with distilled water until neutral $\mathrm{pH}$ of filtrate was obtained. The solid was dried at $80{ }^{\circ} \mathrm{C}$ for $8 \mathrm{~h}$ and calcined at $550{ }^{\circ} \mathrm{C}$ in air flow with the aim to remove organic molecules. $\mathrm{H}$-form sample was obtained via exchange with $\mathrm{NH}_{4} \mathrm{Cl}$ solution and calcined again at $550{ }^{\circ} \mathrm{C}$ in order to eliminate ammonia and to obtain catalyst in acid-form. The obtained H-catalysts were directly used for dimethyl ether synthesis via vapour-phase methanol dehydration. Multifunctional catalysts for one-pot $\mathrm{CO}_{2}$-to-DME process were prepared via gel oxalate co-precipitation of $\mathrm{CuZnZr}$ nitrate $(60 / 30 / 10$ at.\%) in ethanol solutions over $\mathrm{H}$-form zeolite crystals aiming to obtain a hybrid single grain (SG) with $\mathrm{CZZ/zeolite} \mathrm{with} \mathrm{a} \mathrm{weight} \mathrm{ratio} \mathrm{of} \mathrm{1:1.} \mathrm{More} \mathrm{details} \mathrm{about}$ the adopted procedure are reported elsewhere [35]. Furthermore, "homogenous" physical mixtures (PM) constituted by a pre-synthesized CZZ catalyst and a selected zeolite with a weight ratio of 1:1 were also realized.

All of investigated samples were characterized via XRD with APD 2000 Pro diffractometer with a $\mathrm{Cu} \mathrm{K} \alpha$ radiation (40 $\mathrm{kV}, 30 \mathrm{~mA}$ ) in the range 2 theta $=5^{\circ}-50^{\circ}$. The morphology of investigated catalysts was evaluated with both scanning and transmission electron microscopy (SEM - FEI model Inspect, TEM- Philips CM12). Textural properties (e.g. total surface area, micropore volume) were estimated by performing $\mathrm{N}_{2}$ adsorption/desorption isotherms at $77 \mathrm{~K}$ with ASAP 2020 (Micromeritics) instrument. Both $\mathrm{NH}_{3}$-TPD and $\mathrm{H}_{2}$-TPR analyses were performed according to already published procedures [35].

Vapor-phase methanol dehydration was carried out over $\mathrm{H}$ form zeolites in the temperature range $140-200{ }^{\circ} \mathrm{C}$ with a methanol weight hourly space velocity (WHSV) of $4.5 \mathrm{~g}_{\mathrm{MeOH}}$ ${ }^{1} \mathrm{~g}_{\mathrm{cat}}{ }^{-1}$, in a lab-scale apparatus described elsewhere [34]. Before each catalytic test, the reactor was purged with nitrogen at $240{ }^{\circ} \mathrm{C}$ in order to remove moisture from the catalyst. The catalytic activity of investigated hybrid catalysts during onepot $\mathrm{CO}_{2}$-to-DME hydrogenation reaction was investigated in a fixed-bed reactor at $260{ }^{\circ} \mathrm{C}$ and total pressure of $3.0 \mathrm{MPa}$ with a gas hourly space velocity (GHSV) of $8,800 \mathrm{NL} / \mathrm{h} / \mathrm{g}_{\text {cat }}$ by feeding a mixture with a $\mathrm{CO}_{2} / \mathrm{H}_{2} / \mathrm{N}_{2}=3 / 9 / 1$ molar ratio. Prior to each test, the catalyst was reduced in situ at $300{ }^{\circ} \mathrm{C}$ for $1 \mathrm{~h}$ under hydrogen flow at atmospheric pressure. For both the processes, reactor stream was analyzed by GC equipped with flame ionized detector (FID) and a thermal conductivity detector (TCD). 


\section{RESULTS AND DISCUSSION}

\subsection{Characterization}

XRD patterns of synthesized zeolites reported in Figure 1 show that both FER-and MFI-type zeolites were obtained with high purity and crystallinity, regardless of aluminum content. After metal co-precipitation no change on both crystallinity and purity was observed.

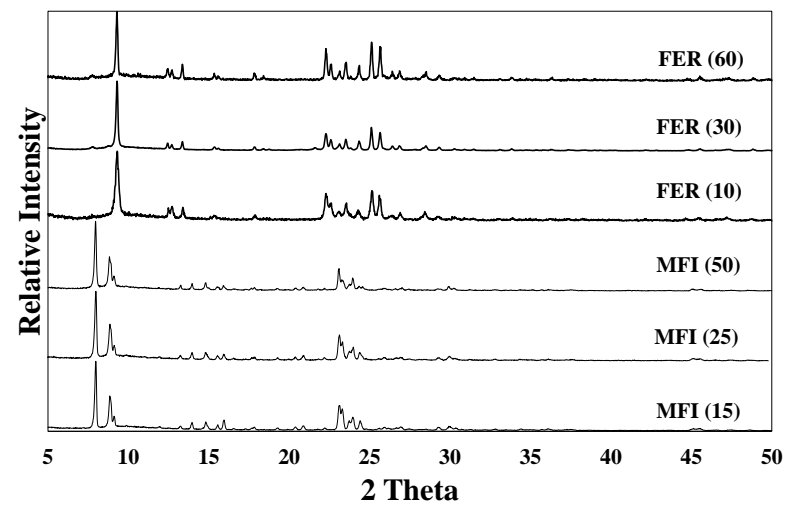

Figure 1. XRD of investigated zeolites

Table 1. Textural properties of investigated materials

\begin{tabular}{cccc}
\hline Sample & $\begin{array}{c}\text { Surface area } \\
\left(\mathrm{m}^{2} / \mathrm{g}\right)\end{array}$ & $\begin{array}{c}\text { Micropore } \\
\text { volume } \\
\left(\mathrm{cm}^{3} / \mathrm{g}\right)\end{array}$ & $\begin{array}{c}\mathrm{d}_{\mathrm{Cu}}^{3} \\
(\mathrm{~nm})\end{array}$ \\
\hline FER (10) & 332 & 0.126 & - \\
CZZ/FER (10) & 217 & 0.052 & 4 \\
FER (30) & 272 & 0.108 & - \\
FER (60) & 275 & 0.110 & - \\
MFI (15) & 365 & 0.098 & - \\
MFI (25) & 360 & 0.118 & - \\
MFI (50) & 350 & 0.110 & - \\
CZZ & 162 & - & 11 \\
\hline
\end{tabular}

1. Determined by Brunauer-Emmett-Teller equation

2. Determined by t-plot model

3. $\mathrm{Cu}$ average particle size determined by $\mathrm{N}_{2} \mathrm{O}$ chemisorption

Table 2. Acidity properties of investigated materials

\begin{tabular}{cccc}
\hline Sample & $\begin{array}{c}\text { Total } \\
\text { acidity } \\
(\mu \mathrm{mol} / \mathrm{g})\end{array}$ & $\begin{array}{c}\text { Weak acid } \\
\text { sites }^{2} \\
(\mu \mathrm{mol} / \mathrm{g})\end{array}$ & $\begin{array}{c}\text { Strong acid } \\
\text { sites }^{3} \\
(\mu \mathrm{mol} / \mathrm{g})\end{array}$ \\
\hline FER (10) & 790 & 277 & 513 \\
CZZ/FER (10) & 500 & 140 & 360 \\
FER (30) & 480 & 67 & 413 \\
FER (60) & 330 & 36 & 294 \\
MFI (15) & 602 & 271 & 331 \\
MFI (25) & 515 & 216 & 299 \\
MFI (50) & 354 & 159 & 195 \\
\hline 1. Determined from desorbed $\mathrm{NH}_{3}$ in the temperature range $100-700{ }^{\circ} \mathrm{C}$ \\
2. Determined from desorbed $\mathrm{NH}_{3}$ in the temperature range $100-300{ }^{\circ} \mathrm{C}$ \\
3. Determined from desorbed $\mathrm{NH}_{3}$ in the temperature range $300-700{ }^{\circ} \mathrm{C}$
\end{tabular}

The main textural properties of the investigated materials are reported in Table 1. Both total surface area and micropore volume of bare zeolites are in agreement with the value reported in literature for similar materials. After coprecipitation of metals, both surface are and micropore volume are strongly reduced, probably due to a partial pore blocking of zeolites due to the presence of $\mathrm{CuCnZr}$ particles. $\mathrm{N}_{2} \mathrm{O}$ measurements indicate that smaller copper particles are present on FER-type zeolite suggesting that there is some effect of the presence of zeolite on copper dispersion.

Table 2 reports the acidity of investigated samples. Considering bare zeolites, total acidity increases accordingly with aluminium content. Furthermore, MFI-type zeolites disclose a similar fraction of weak (about $45 \%$ ) and strong sites (about $55 \%$ ). Similar distribution was observed for FER (10). On the contrary, both FER (30) and FER (60) disclose a higher fraction of strong acid sites (more than $85 \%$ ). FT-IR analysis (not shown) carried out with both carbon monoxide and $\mathrm{D}_{3}$-acetonitrile reveals that only FER (10) possesses Lewis acid sites with a Lewis/Brønsted ratio equals to 0.33 , whilst mainly Brønsted acid sites are present on the other FER-and MFI-type samples.

\subsection{Catalytic tests}

\section{(1) Methanol-to-DME}

Methanol conversion as a function of reaction temperature for all of investigated zeolites is reported in Figure 2. In the entire range of temperature only DME was observed with no formation of by-products.

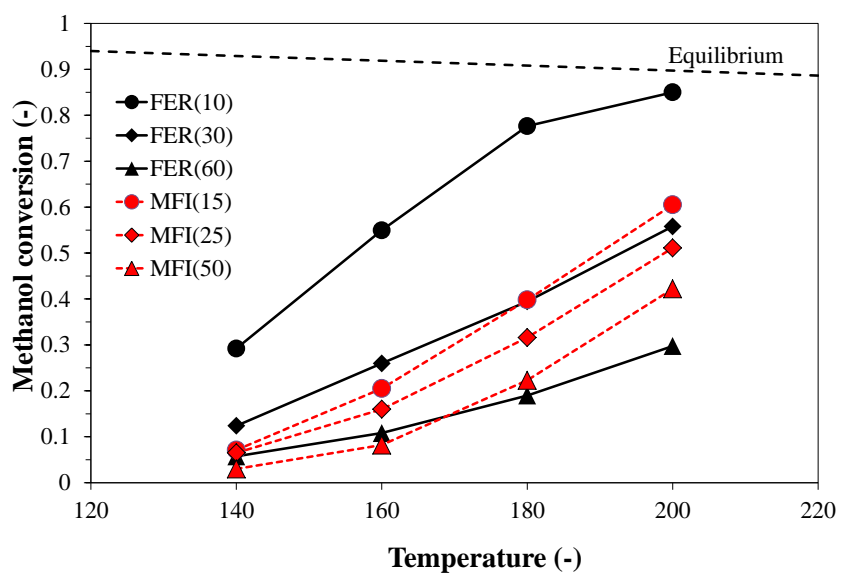

Figure 2. Methanol conversion as a function of reaction temperature for the investigated $\mathrm{H}$-zeolites

Results indicate that catalytic activity during methanol dehydration to DME reaction strongly depends on the acidity of zeolite. In fact, methanol conversion follows the order FER (10) $>$ FER (30)>FER (60) for FER-type zeolites and MFI (15)>MFI (25)>MFI (50) for MFI-type zeolites. On the whole, FER (10) zeolite discloses the highest activity, approaching to the theoretical equilibrium value at the $200{ }^{\circ} \mathrm{C}$, in agreement with the highest value of acidity. On the other hand, although MFI(15) possesses a higher concentration of total acid sites, it shows a lower activity than FER(30) especially at low temperature. Similar behavior is also disclosed for FER (60) and MFI (50) samples. A different trend is observed at temperature higher than $180^{\circ} \mathrm{C}$ as both MFI (15) and MFI (50) exhibit a higher activity than FER (30) and FER (60), respectively.

Such behavior may be related to weak/strong acid sites distribution. In fact, the activity order seems to follow strong acid sites concentration at lower temperature and total acid sites concentrations at higher temperature. In fact, it is reasonable to conclude that only strong acid sites are active at lower temperature, whilst weak acid sites became able to catalyze the dehydration of methanol at temperature above or 
equals to $180{ }^{\circ} \mathrm{C}$. At this temperature turnover frequency may be then calculated and results are reported in Table 3. Turnover frequency follows the order

(60)

FER (10)>FER (30)>MFI (15)>MFI (50)>MFI (25)>FER

revealing that FER (10) and MFI (15) are the most efficient catalysts among the FER-type and MFI-type zeolites, respectively.

Table 3 reports also the apparent activation energies $\left(E_{\text {app }}\right)$ for the investigated catalysts, indicating that the activation barrier is always lower for FER-type materials and it decreases as the total acidity increases.

Table 3. Turnover frequency and apparent activation energy of investigated zeolites for methanol-to-DME reaction

\begin{tabular}{ccc}
\hline Sample & $\begin{array}{c}\text { Turnover frequency } \\
\text { at } 180^{\circ} \mathrm{C} \\
\left(\text { mol }_{\text {DME }} / \mathrm{mol}_{\mathrm{H}+} / \mathrm{h}\right)\end{array}$ & $\begin{array}{c}\text { Apparent } \\
\text { activation energy } \\
(\mathrm{kJ} / \mathrm{mol})\end{array}$ \\
\hline FER (10) & 69 & 38 \\
FER (30) & 58 & 45 \\
FER (60) & 41 & 47 \\
MFI (15) & 46 & 58 \\
MFI (25) & 43 & 62 \\
MFI (50) & 44 & 78 \\
\hline
\end{tabular}

\section{(2) $\mathrm{CO}_{2}$-to-DME}

As reported in the previous paragraph, FER (10) may be considered as the most active catalyst for methanol dehydration reaction step, among the investigated FER-type and MFI-type zeolites, respectively. Therefore, one-pot $\mathrm{CO}_{2-}$ to-DME reaction was carried out at $260{ }^{\circ} \mathrm{C}$ and 30 bar by using FER (10) as acid catalyst in three different multifunctional catalytic bed configurations: CZZ-FER (10) dual bed (DB), physical mixture (PM) and hybrid single grain (SG). Figure 3 reports the results of catalytic tests under one-pot $\mathrm{CO}_{2}$ hydrogenation to DME conditions.

$\mathrm{CO}_{2}$ conversion is about $18 \%$ for DB system, and it increases at 20 and $22 \%$ for PM and SG systems, respectively. Catalytic tests carried out over $\mathrm{CZZ}$ reveal a similar $\mathrm{CO}_{2}$ conversion and $\mathrm{CO}$ selectivity observed for DB system, suggesting that no significant catalytic improvement is obtained when a dual bed is used.

Moreover, reactor bed configuration also strongly affects product distribution.

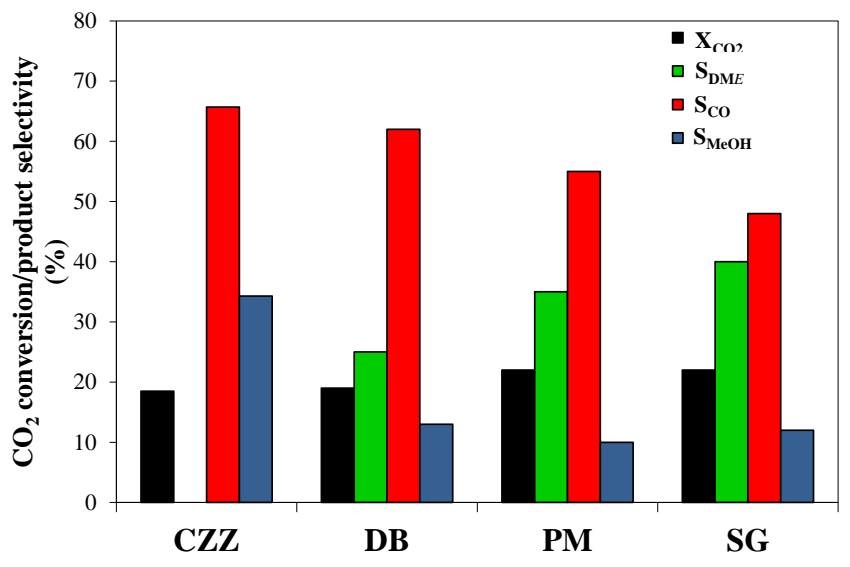

Figure 3. $\mathrm{CO}_{2}$ conversion and selectivity towards DME $\left(\mathrm{S}_{\mathrm{DME}}\right), \mathrm{CO}\left(\mathrm{S}_{\mathrm{CO}}\right)$ and methanol $\left(\mathrm{S}_{\mathrm{MeOH}}\right)$ for the investigated CZZ/FER(10)-DB, -PM and -SG systems and CZZ catalyst $\left(\mathrm{T}_{\mathrm{R}}: 260{ }^{\circ} \mathrm{C}, \mathrm{P}_{\mathrm{R}}: 30\right.$ bar, GHSV: $\left.8800 \mathrm{NL} / \mathrm{h} / \mathrm{g}_{\text {cat }}\right)$
DME selectivity is lower for dual bed reactor that exhibits a DME selectivity of $25 \%$, meaning that only $5 \%$ of carbon is converted into dimethyl ether. DME selectivity is increased up to $35 \%$ when both CZZ and FER (10) powders are "homogenously" mixed.

When hybrid single grain is used, catalytic performances are further improved, leading to a DME selectivity of $40 \%$, meaning that more than $10 \%$ of carbon is converted towards the desired product. Such result clearly shows that the efficiency of catalytic bed strongly depends on the possibility to have an intimate cooperation between metallic and acid sites. In that sense, hybrid single grain system should facilitate mass transfer phenomena, so promoting a more rapid dehydration of methanol towards dimethyl ether on neighbouring sites, and bring out the thermodynamic advantages of one-pot process. On the whole, the space-time yield calculated for the investigated system was 732,640 and $395 \mathrm{~g}$ DME $/ \mathrm{h} / \mathrm{kg}_{\text {cat }}$ for $\mathrm{SG}$, PM and DB systems, respectively, again highlighting the crucial role of metal-acid proximity in the synthesis of dimethyl ether.

\section{CONCLUSIONS}

In this work, FER-type and MFI-type zeolites characterized by different structure and acidity were used as catalysts for the vapor-phase dehydration of methanol into dimethyl ether. A $\mathrm{Si} / \mathrm{Al}$ ratio as low as 10 in the FER-type zeolites allowed to obtain the best performance, showing a DME turnover frequency of $69 \mathrm{~mol}_{\mathrm{DME}} / \mathrm{mol}_{\mathrm{H}+} / \mathrm{h}$. Among MFI-type zeolites, crystals synthesized with a $\mathrm{Si} / \mathrm{Al}=15$ disclose the highest catalytic activity. FER (10) zeolite was then used as acid catalyst for one-pot $\mathrm{CO}_{2}$ hydrogenation to DME coupled with $\mathrm{CuZnZr}$ (CZZ) metallic system. Among several catalytic bed configurations assessed (i.e. dual bed, physical mixture and hybrid single grain), the dual bed reactor resulted to be the less effective configuration, whilst hybrid single grain prepared via gel-oxalate co-precipitation of metal precursors over zeolite crystals exhibited significant better catalytic performance, with a DME productivity of $732 \mathrm{~g}_{\mathrm{DME}} / \mathrm{h} / \mathrm{kg}_{\text {cat }}$, almost doubled than that obtained with double bed configuration.

\section{REFERENCES}

[1] Olah GA. (2005). Beyond oil and gas: The methanol economy. Angew. Chem. Int. Ed 44(18): 2636-2639. https://doi.org/10.1002/anie.200462121

[2] Perathoner S, Centi G. (2014). CO2 recycling: A key strategy to introduce green energy in the chemical production chain. ChemSusChem 7(5): 1274-1282. https://doi.org/10.1002/cssc.201300926

[3] Arcoumanis C, Bae C, Crookes R, Kinoshita E. (2008). The potential of di-methyl ether (DME) as an alternative fuel for compression-ignition engines: A review. Fuel 87(7):

1014-1030. https://doi.org/10.1016/j.fuel.2007.06.007

[4] Park SH, Lee CS. (2014). Applicability of diemthyl ether (DME) in a compression ignition engine as an alternative fuel. Energ. Conv. Manag 86: 848-863. https://doi.org/10.1016/j.enconman.2014.06.051

[5] Semelsberg TA, Borup RL, Greene HL. (2006). Dimethyl ether (DME) as an alternative fuel. J. Power Sourc 156(2): 
https://doi.org/10.1016/j.jpowsour.2005.05.082

[6] Azizi Z, Rezaeimanesh M, Tohidian T, Rahimpour MR. (2014). Dimethyl ether: A reviee of technologies and production challenges. Chem. Eng. Process. Proc. Int 82: 150-172. https://doi.org/ 10.1016/j.cep.2014.06.007

[7] Sun J, Yang G, Yoneyama Y, Tsubaki N. (2014). Catalysis chemistry of dimethyl ether synthesis. ACS Catal $4(10)$ :

3346-3356. https://doi.org/10.1021/cs500967j

[8] Yoon ES, Han C. (2009). A review of sustainable energy - recent development and future prospects of dimethyl ether (DME) Comp. Aid. Chem. Eng. 27: 169-175. https://doi.org/10.1016/S1570-7946(09)70249-4.

[9] Graves C, Ebbesen SD, Mogensen M, Lackner KS. (2011). Sustainable hydrocarbon fuels by recycling $\mathrm{CO}_{2}$ and $\mathrm{H}_{2} \mathrm{O}$ with renewable or nuclear energy. Renew. Sus. Energ. $\quad$ Rev 15(1): 1-23. https://doi.org/10.1016/j.rser.2010.07.014.

[10] Aresta M, Dibenedetto A, Angelini A. (2013). The changing paradigm in $\mathrm{CO}_{2}$ utilization. J. $\mathrm{CO}_{2}$ Util 3-4: 65-73. https://doi.org/10.1016/j.jcou.2013.08.001

[11] Jia G, Tan Y, Han Y. (2006). A comparative study on the thermodynamics of dimethyl ether synthesis from $\mathrm{CO}$ hydrogenation and $\mathrm{CO}_{2}$ hydrogenation. Ind. Eng. Chem. Res 45(3):

1152-1159. https://doi.org/10.1021/ie050499b

[12] An X, Zuo YZ, Zhang Q, Wang D, Wang JF. (2008). Dimethyl ether synthesis from $\mathrm{CO}_{2}$ hydrogenation on a $\mathrm{CuO}-\mathrm{ZnO}-\mathrm{Al}_{2} \mathrm{O}_{3}-\mathrm{ZrO}_{2} / \mathrm{HZSM}-5$ bifucntional catalyst. Ind. Eng. Chem. Res 47(17): 6547-6554. https://doi.org/10.1021/ie800777t

[13] Bourzutschky JA, Homs N, Bell AT. (1990). Hydrogenation of $\mathrm{CO}_{2}$ and $\mathrm{CO}_{2} / \mathrm{CO}$ mixtures over copper-containing catalysts. J. Catal 124(1): 73-85. https://doi.org/10.1016/0021-9517(90)90104-R

[14] Brown DM, Bhatt BL, Hsiung TH, Lewnard JJ, Waller FJ. (1991). Novel technology fior the synthesis of dimethyl ether from syngas. Catal. Today 8(3): 279-304. https://doi.org/10.1016/0920-5861(91)80055-E

[15] Olah GA, Goeppert A, Prakash GK. (2009). Chemical recycling of carbon dioxide to methanol and dimethyl ether: from greenhouse gas to renewable, environmentally carbon neutral fuels and synthetic hydrocarbons. J. Org. Chem 74(2): 487-498. https://doi.org/10.1021/jo801260f

[16] Li Y, Wang T, Yin X, Wu C, Ma L, Li H, Lv Y, Sun L. (2010). 100 t/a-scale demonstration of direct dimethyl ether synthesis from corncob-derived syngas. Ren. Energ. $35(3)$ 583-587. https://doi.org/10.1016/j.renene.2009.08.002.

[17] Ge Q, Huang Y, Qiu F, Li S. (1998). Bifunctional catalysts for conversion of synthesis gas to dimethyl ether. Appl. Catal. A: Gen 167(1): 23-30. https://doi.org/10.1016/S0926-860X(97)00290-1

[18] Catizzone E, Bonura G, Migliori M, Frusteri F, Giordano $\mathrm{G}$. (2018). $\mathrm{CO}_{2}$ recycling to dimethyl ether: state-of-theart and perspectives. Molecules 23(1): 31-58. https://doi.org/10.3390/molecules23010031

[19] Sierra I, Erena J, Aguayo T, Olazar M, Bilbao, J. (2010). Deactivation kinetics for direct dimethyl ether synthesis on a $\mathrm{CuO}-\mathrm{ZnO}-\mathrm{Al}_{2} \mathrm{O}_{3} / \gamma-\mathrm{Al}_{2} \mathrm{O}_{3}$ catalysts. Ind. Eng. Chem. $\begin{array}{llll}\text { Res } & \text { vol. 49(2): 481-489. }\end{array}$ https://doi.org/10.1021/ie900978a

[20] Naik SP, Ryu T, Bui V, Miller JD, Drinnan N, Zmierczak
W. (2011). Synthesis of DME from $\mathrm{CO}_{2} / \mathrm{H}_{2}$ gas mixture. Chem. Eng. J 167(1): 362-368. https://doi.org/10.1016/j.cej.2010.12.087

[21] Abu-Dahrieh J, Rooney D, Goguet A, Saih Y. (2012). Activity and deactivation studies for direct dimethyl ether synthesis using $\mathrm{CuO}-\mathrm{ZnO}-\mathrm{Al}_{2} \mathrm{O}_{3}$ with $\mathrm{NH} 4 \mathrm{ZSM}-5$, HZSM-5 or $\gamma-\mathrm{Al}_{2} \mathrm{O}_{3}$. Chem. Eng. J 203(1): 201-211. https://doi.org/10.1016/j.cej.2012.07.011

[22] Bonura G, Migliori M, Frusteri L, Cannilla C, Catizzone E, Giordano G. Frusteri, F. (2018). Acidity control of zeolite functionality on activity and stability of hybrid catalysts during DME production via $\mathrm{CO}_{2}$ hydrogenation. $\begin{array}{lllll}\text { J. } & \mathrm{CO}_{2} & \text { Util } & \text { 24: } & \text { 398-406. }\end{array}$ https://doi.org/10.1016/j.jcou.2018.01.028

[23] Bonura G, Frusteri F, Cannilla C, DragoFerrante G, Aloise A, Catizzone E, Migliori M, Giordano G. (2016). Catalytic features of $\mathrm{CuZnZr-zeolite} \mathrm{hybrid} \mathrm{systems} \mathrm{for}$ the direct $\mathrm{CO}_{2}$-to-DME hydrogenation reaction. Catal. Today 277: 48-54. https://doi.org/10.1016/j.cattod.2016.02.013

[24] Catizzone E, Migliori M, Purita A, Giordano G. (2019). Ferrierite vs. $\gamma-\mathrm{Al}_{2} \mathrm{O}_{3}$ : The superiority of zeolites in terms of water-resistance in vapour-phase dehydration of methanol to dimethyl ether. J. Energ. Chem 30: 162-169. https://doi.org/10.1016/j.jechem.2018.05.004

[25] Migliori M, Catizzone E, Aloise A, Bonura G, GomezHortiguela L, Frusteri L, Cannilla C, Frusteri F, Giordano G. (2018). New insights about coke deposition in methanol-to-DME reaction over MOR-, MFI- and FERtype zeolites. J. Ind. Eng. Chem 68: 196-208. https://doi.org/10.1016/j.jiec.2018.07.046

[26] Guisnet M, Magnoux P. (1989). Coking and deactivation of zeolites: Influence of the pore structure. Appl. Catal 54(1): $\quad 1-27 . \quad$ https://doi.org/10.1016/S01669834(00)82350-7.

[27] Derouane EG. (1985). Factor affecting the deactivation of zeolites by coking. Stud. Surf. Sci. Catal 20: 221-240. https://doi.org/10.1016/S0167-2991(09)60173-7

[28] Corma A. (1995). Inorganic solid acids and their use in acid-catalyzed hydrocarbon reactions. Chem. Rev 95: 559-614. https://doi.org/10.1021/cr00035a006

[29] Corma A. (2003). State of the art and future challenges of zeolites as catalysts. J. Catal 216(1-2): 298-312. https://doi.org/10.1016/S0021-9517(02)00132-X

[30] Catizzone E, Migliori M, Aloise A, Lamberti R, Giordano G. (2019). Hierarchical low Si/Al ratio ferrierite zeolite by sequential postsynthesis treatment: catalytic assessment in dehydration reaction of methanol. J. Chem 2019. https://doi.org/10.1155/2019/3084356

[31] Catizzone E, Van DS, Bianco M, Di-Michele A, Aloise A, Migliori M, Valtchev V, Giordano, G. (2019). Catalytic application of ferriertienanocrystals in vapourphase dehyrdation of methanol to dimethyl ether. Appl. $\begin{array}{llll}\text { Catal. } & \text { B.: } & \text { 273-282. }\end{array}$ https://doi.org/10.1016/j.apcatb.2018.10.060

[32] Prasad PS, Bae JW, Kang SH, Lee YJ, Jun KW. (2008). Single-step synthesis of DME from syngas on $\mathrm{Cu}-\mathrm{ZnO}$ $\mathrm{Al}_{2} \mathrm{O}_{3}$ /zeolite bifunctional catalysts: The superiority of ferrierite over the other zeolites. Fuel Process. Technol 89(12): 1281-1286. https://doi.org/10.1016/j.fuproc.2008.07.014.

[33] Catizzone E, Aloise A, Migliori M, Giordano G. (2007). From 1-D to 3-D zeolite structures: performance assessment in catalysis of vapour-phase methanol 
dehydration to DME. Microp. Mesopo. Mater 243: 102111. https://doi.org/10.1016/j.micromeso.2017.02.022

[34] Migliori M, Aloise A, Catizzone E, Giordano G. (2014). Kinetic analysis of methanol to dimethyl ether reaction over H-MFI catalysts. Ind. Eng. Chem. Res 53(38): 14885-14891. https://doi.org/10.1021/ie502775u
[35] Bonura G, Cannill C, Frusteri L, Mezzapica A, Frusteri F. (2017). DME production by $\mathrm{CO}_{2}$ hydrogenation: key dactors affecting the behaviour of $\mathrm{CuZnZr} /$ ferrierite catalysts. Catal. Today 281(1): 337-344. https://doi.org/10.1016/j.cattod.2016.05.057 